\title{
Quantitative Determination of Flavonoids and Chlorogenic Acid in the Leaves of Arbutus unedo L. Using Thin Layer Chromatography
}

\author{
Željan Maleš, ${ }^{1}$ Darija Šarić, ${ }^{2}$ and Mirza Bojićc ${ }^{1}$ \\ ${ }^{1}$ University of Zagreb, Faculty of Pharmacy and Biochemistry, A. Kovačića 1, 10000 Zagreb, Croatia \\ ${ }^{2}$ Agency for Medicinal Products and Medical Devices of Croatia, Ksaverska cesta 4, 10000 Zagreb, Croatia \\ Correspondence should be addressed to Mirza Bojić; mirza.bojic@gmail.com
}

Received 26 May 2013; Accepted 11 July 2013

Academic Editor: Shixin Deng

Copyright (c) 2013 Željan Maleš et al. This is an open access article distributed under the Creative Commons Attribution License, which permits unrestricted use, distribution, and reproduction in any medium, provided the original work is properly cited.

The plant species Arbutus unedo shows numerous beneficial pharmacological effects (antiseptic, antidiabetic, antidiarrheal, astringent, depurative, antioxidant, antihypertensive, antithrombotic, and anti-inflammatory). For the medicinal use, standardization of extracts is a necessity, as different compounds are responsible for different biological activities. In this paper, we analyze monthly changes in the content of quercitrin, isoquercitrin, hyperoside, and chlorogenic acid. Methanolic extracts of the leaves are analyzed by HPTLC for the identification and quantification of individual polyphenol, and DPPH test is used to determine antioxidant activity. Based on the results obtained, the leaves should be collected in January to obtain the highest concentrations of hyperoside and quercitrin $(0.35 \mathrm{mg} / \mathrm{g}$ and $1.94 \mathrm{mg} / \mathrm{g}$, resp.), in June, July, and October for chlorogenic acid (1.45-1.46 mg/g), and for the fraction of quercitrin and isoquercitrin in November $(1.98 \mathrm{mg} / \mathrm{g}$ and $0.33 \mathrm{mg} / \mathrm{g}$, resp.). Optimal months for the collection of leaves with the maximum recovery of individual polyphenol suggested in this work could direct the pharmacological usage of the polyvalent herbal drugs.

\section{Introduction}

Arbutus unedo L. (Ericaceae, English strawberry tree) is an evergreen shrub or a small tree reaching up to $12 \mathrm{~m}$ in height. It is found mainly in European Mediterranean region growing in maquis, evergreen scrub, woodland margins, and on rocky slopes. The leaves of $A$. unedo are alternate, simple, oblanceolate, dark green, leathery, short-stalked, and toothed. The flowers are bell shaped, with recurved lobes, $8-9 \mathrm{~mm}$ long, white, often tinged with pink or green, and honey scented. The fruits are globose berries about 15-20 mm in diameter, ripening through yellow to scarlet and deep crimson. Since the fruits take about 12 months to ripen, a tree carries mature fruits and flowers at the same time, and the appearance of both during winter months also makes this plant very popular for specimen plantings [1,2].

The leaves of $A$. unedo are used as a urinary antiseptic, antidiabetic, antidiarrheal, astringent, depurative, antioxidant, antihypertensive, antithrombotic, anti-inflammatory agent [3-8]. Chemical investigations of leaves and fruits show the presence of essential oil, flavonoids, proanthocyanidins, iridoid glucosides, sugars, nonvolatile and phenolic acids, vitamins $\mathrm{C}$ and $\mathrm{E}$ and carotenoids [9-13].

As a pharmacological activity can rarely be attributed to a group of compounds as it is the case with polyphenols and antioxidant activity, the identification and quantification of individual compounds responsible for a biological activity are of interest. The objective of this paper was the identification and quantification of chlorogenic acid and flavonoids: quercitrin, isoquercitrin, and hyperoside using a simple thin layer chromatography technique.

\section{Experimental}

2.1. Plant Materials, Reagents, Chemicals, and Solutions. Each month in the year of 2003 the leaves of ten A. unedo plants were collected on five different locations on the island of Dugi 
otok, Božava municipality (44 $\left.8^{\circ} 30^{\prime \prime} \mathrm{N}, 14^{\circ} 54^{\prime} 30^{\prime \prime} \mathrm{E}\right)$. Voucher specimens (no. 99450-99461) were deposited at the Department of Pharmaceutical Botany, Faculty of Pharmacy and Biochemistry, University of Zagreb. Solvents of the analytical grade were obtained from Kemika (Croatia) and standards (quercitrin, isoquercitrin, hyperoside, and chlorogenic acid) were purchased from C. Roth (Germany). 2,2Diphenyl-1-picrylhydrazyl was supplied by Sigma-Aldrich (USA) and HPTLC silica gel 60 F254 by Merck (Germany).

\subsection{Sample and Standard Preparation. Extracts of A. unedo} were prepared by the reflux extraction of leaves powder in methanol for 5 minutes; final concentration being $0.1 \mathrm{~g} / \mathrm{mL}$. The standards of polyphenols were prepared as $1 \mathrm{mg} / \mathrm{mL}$ solutions in methanol.

2.3. Thin Layer Chromatography. Thin layer chromatography was performed on $10 \times 20 \mathrm{~cm}$ HPTLC silica gel 60 F254 plates (Merck, Germany). Ethyl acetate-formic acid-acetic acid-water in volume ratio $100: 11: 11: 26$ was used as mobile phase [14]. After development plates were air dried and recorded at 254 and $366 \mathrm{~nm}$, identification and quantification were performed by TLC densitometry using CAMAG TLC Scanner 3 and WinCATS software version 1.3.4 (Switzerland). Quantification was performed using calibration curves (peak area of chromatogram versus mass of standard applied in the form of band) for individual standard in triplicate.

2.4. DPPH Test. Antioxidant activity was assessed using stable free radical 2,2-diphenyl-1-picrylhydrazyl (DPPH). DPPH solution was prepared by dissolving DPPH in ethanol to obtain the final concentration of $0.3 \mathrm{mM}$. Decolorization of DPPH in the presence of extract (100:1 volume ration) was measured on Varian Cary 50 Bio spectrophotometer (USA). Antioxidant activity (AA) was expressed as a percentage of quenching of the stable free radical at $\lambda=518 \mathrm{~nm}$ as follows:

$$
\mathrm{AA}=\frac{\left(A_{0}-A\right)}{A_{0}} \times 100,
$$

where $A_{0}$ represents the absorbance of blank (methanol) and $A$ absorbance of the extract measured 1 minute after mixing.

\section{Results and Discussion}

Qualitative analysis of polyphenols in leaves and fruits of A. unedo [14] showed presence of nine bands in the methanol extracts. Seven polyphenol standards were used and four flavonoids and chlorogenic acid were identified, out of which we were able to determine the content (quantify) of chlorogenic acid, quercitrin, isoquercitrin, and hyperoside.

Identification of each polyphenol was based on the color of the band observed under $\lambda=366 \mathrm{~nm}, R_{F}$ value, and matching UV-Vis spectra in situ with the standard used (Table 1).

Volumes of extracts applied to the plate were adjusted to correspond to ranges of linearity for individual polyphenol that were $0.2-1.6 \mu \mathrm{g}$ per band for chlorogenic acid, 1.0$5.0 \mu \mathrm{g}$ per band for quercitrin, $2.5-12.5 \mu \mathrm{g}$ per band for
TABLE 1: Parameters of identification of the polyphenols analyzed.

\begin{tabular}{lcc}
\hline Polyphenol & $R_{F}$ & Color under $\lambda=366 \mathrm{~nm}$ \\
\hline Quercitrin & 0.80 & Yellow-green \\
Isoquercitrin & 0.64 & Yellow-green \\
Hyperoside & 0.57 & Yellow-green \\
Chlorogenic acid & 0.49 & Blue \\
\hline
\end{tabular}

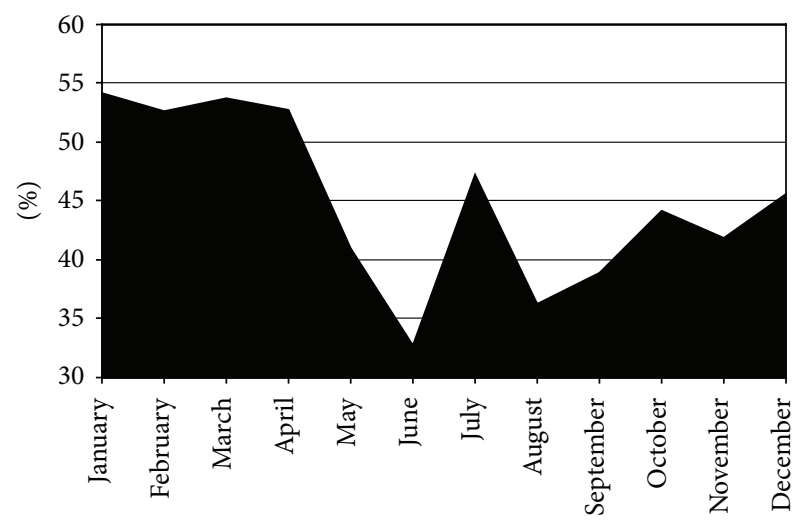

FIGURE 1: Variation of antioxidant activity expressed in percentages during the year.

isoquercitrin, and $0.2-0.6 \mu \mathrm{g}$ per band for hyperoside. The results of HPTLC quantification of an individual polyphenol are presented in Table 2.

Compared to the results of the total flavonoids of 1.30$2.00 \mathrm{~g}$ per $100 \mathrm{~g}$ of dried leaves from our previous study [14], quercitrin, isoquercitrin, and hyperoside $(2.38 \mathrm{mg} / \mathrm{g}$ - sum of individual flavonoids for June, Table 2) can be accounted for up to $12 \%$ of dry powder. However, it should be noticed that methods for determination of total flavonoids usually use hydrolyzed extracts, meaning that aglycones are analyzed, whereas all the analyzed polyphenols in this work present flavonoid glycosides.

As suggested by Oliveira et al. [15], methanolic extracts have greater antioxidant activity compared to ethanolic and water based. The antioxidant activity values of methanolic extracts of $A$. unedo were determined during a period of 12 months (Figure 1).

The results of the antioxidant activity vary with the month observed and cannot be attributed to any of the analyzed polyphenols individually $\left(r^{2}<0.25\right)$; rather it presents the overall activity of the total extracted polyphenols including phenolic acids and flavonoids other than analyzed chlorogenic acid, quercitrin, isoquercitrin and hyperoside. These flavonoids are attributed up to only $12 \%$ of total flavonoids.

Specific pharmacological activity is usually the result of a specific substance; for example, the inhibition of 3-hydroxy3-methylglutaryl coenzyme A reductase can be attributed to quercetin, hyperoside, rutin, and chlorogenic acid fractions of Crataegus pinnatifida Bge. [16]. Thus, to achieve a specific action of the extracts of $A$. unedo, leaves should be collected during the months when the concentration of individual substance responsible for specific action is the highest. This means, based on the results obtained, that the leaves 
TABLE 2: Content of individual polyphenol during the year in the leaves of $A$. unedo expressed in mg per g of dry sample.

\begin{tabular}{|c|c|c|c|c|}
\hline & Quercitrin & Isoquercitrin & Hyperoside & Chlorogenic acid \\
\hline January & $1.94 \pm 0.08$ & nd & $0.35 \pm 0.03$ & $0.70 \pm 0.09$ \\
\hline February & $1.34 \pm 0.22$ & nd & $0.12 \pm 0.03$ & $0.76 \pm 0.09$ \\
\hline March & $1.38 \pm 0.21$ & nd & nd & $1.06 \pm 0.19$ \\
\hline April & $1.38 \pm 0.17$ & nd & $0.11 \pm 0.03$ & $1.13 \pm 0.07$ \\
\hline May & $1.21 \pm 0.05$ & nd & $0.11 \pm 0.02$ & $1.06 \pm 0.12$ \\
\hline June & $2.20 \pm 0.17$ & $0.07 \pm 0.01$ & $0.11 \pm 0.04$ & $1.45 \pm 0.34$ \\
\hline July & $1.56 \pm 0.09$ & nd & nd & $1.46 \pm 0.13$ \\
\hline August & $1.78 \pm 0.30$ & $0.09 \pm 0.05$ & $0.21 \pm 0.01$ & $1.11 \pm 0.14$ \\
\hline September & $1.74 \pm 0.14$ & nd & nd & $0.79 \pm 0.16$ \\
\hline October & $1.78 \pm 0.04$ & nd & nd & $1.45 \pm 0.59$ \\
\hline November & $1.98 \pm 0.21$ & $0.33 \pm 0.08$ & $0.16 \pm 0.01$ & $0.76 \pm 0.11$ \\
\hline December & $1.46 \pm 0.26$ & $0.13 \pm 0.09$ & $0.24 \pm 0.01$ & $0.61 \pm 0.05$ \\
\hline
\end{tabular}

Results expressed as mean \pm standard deviation. nd: not detected.

should be collected in January to obtain the highest concentrations of hyperoside and quercitrin $(0.35 \mathrm{mg} / \mathrm{g}$ and $1.94 \mathrm{mg} / \mathrm{g}$, resp.), in June, July, and October for chlorogenic acid $(1.45-1.46 \mathrm{mg} / \mathrm{g})$, and for the fraction of quercitrin and isoquercitrin in November $(1.98 \mathrm{mg} / \mathrm{g}$ and $0.33 \mathrm{mg} / \mathrm{g}$, resp.).

\section{Conclusion}

Different studies have shown beneficial effects of $A$. unedo for human health and suggested the usage of standardized extracts in medicinal products. Although antioxidant activity well correlates with the total content of polyphenols, phenolic acids, and flavonoids [15], a specific action, for example, an antiaggregatory [6] or an anti-inflammatory action [7], is probably the consequence of specific compound(s) to which extracts should be standardized. For this purposes the thin layer chromatography presents simple and readily available technique.

\section{Conflict of Interest}

The authors declare no conflict of interests.

\section{Acknowledgments}

This work was supported by the Ministry of Science, Education and Sports of the Republic of Croatia, Grant nos. 0060061117-1237 and 006-0061117-1239.

\section{References}

[1] R. Domac, Flora of Croatia: Manual For Determination of Plants, Školska knjiga, Zagreb, Croatia, 2002.

[2] Č. Šilić, Atlas of Trees and Shrubs, Svjetlost, Sarajevo, Bosnia, 3rd edition, 1988.

[3] S. Afkir, T. B. Nguelefack, M. Aziz et al., "Arbutus unedo prevents cardiovascular and morphological alterations in LNAME-induced hypertensive rats. Part I: cardiovascular and renal hemodynamic effects of Arbutus unedo in L-NAMEinduced hypertensive rats," Journal of Ethnopharmacology, vol. 116 , no. 2, pp. 288-295, 2008.

[4] D. Andrade, C. Gil, L. Breitenfeld, F. Domingues, and A. P. Duarte, "Bioactive extracts from Cistus ladanifer and Arbutus unedo L," Industrial Crops and Products, vol. 30, no. 1, pp. 165$167,2009$.

[5] M. Bnouham, F. Z. Merhfour, A. Legssyer, H. Mekhfi, S. Maâllem, and A. Ziyyat, "Antihyperglycemic activity of Arbutus unedo, Ammoides pusilla and Thymelaea hirsuta," Pharmazie, vol. 62, no. 8, pp. 630-632, 2007.

[6] M. El Haouari, J. J. López, H. Mekhfi, J. A. Rosado, and G. M. Salido, "Antiaggregant effects of Arbutus unedo extracts in human platelets," Journal of Ethnopharmacology, vol. 113, no. 2, pp. 325-331, 2007.

[7] S. Mariotto, E. Esposito, R. Di Paola et al., "Protective effect of Arbutus unedo aqueous extract in carrageenan-induced lung inflammation in mice," Pharmacological Research, vol. 57, no. 2, pp. 110-124, 2008.

[8] A. Pabuçcuoǧlu, B. Kivçak, M. Baş, and T. Mert, "Antioxidant activity of Arbutus unedo leaves," Fitoterapia, vol. 74, no. 6, pp. 597-599, 2003.

[9] L. Barros, A. M. Carvalho, J. S. Morais, and I. C. F. R. Ferreira, "Strawberry-tree, blackthorn and rose fruits: detailed characterisation in nutrients and phytochemicals with antioxidant properties," Food Chemistry, vol. 120, no. 1, pp. 247-254, 2010.

[10] B. Kivcak, T. Mert, B. Demirci, and K. H. C. Baser, "Composition of the essential oil of Arbutus unedo," Chemistry of Natural Compounds, vol. 37, no. 5, pp. 445-446, 2001.

[11] P. Lebreton and C. Bayet, "The physiological and biochemical variability of the strawberry tree Arbutus unedo L. (Ericaceae)," Acta Pharmaceutica, vol. 52, no. 2, pp. 83-90, 2002.

[12] M. M. Özcan and H. Haciseferogullan, "The strawberry (Arbutus unedo L.) fruits: chemical composition, physical properties and mineral contents," Journal of Food Engineering, vol. 78, no. 3, pp. 1022-1028, 2007.

[13] K. Pallauf, J. C. Rivas-Gonzalo, M. D. del Castillo, M. P. Cano, and S. de Pascual-Teresa, "Characterization of the antioxidant composition of strawberry tree (Arbutus unedo L.) fruits," Journal of Food Composition and Analysis, vol. 21, no. 4, pp. 273281, 2008. 
[14] Ž. Maleš, M. Plazibat, V. B. Vundać, and I. Žuntar, "Qualitative and quantitative analysis of flavonoids of the strawberry treeArbutus unedo L. (Ericaceae)," Acta Pharmaceutica, vol. 56, no. 2, pp. 245-250, 2006.

[15] I. Oliveira, V. Coelho, R. Baltasar, J. A. Pereira, and P. Baptista, "Scavenging capacity of strawberry tree (Arbutus unedo L.) leaves on free radicals," Food and Chemical Toxicology, vol. 47, no. 7, pp. 1507-1511, 2009.

[16] X.-L. I. Ye, W.-W. Huang, Z. Chen et al., "Synergetic effect and structure-activity relationship of 3-hydroxy-3-methylglutaryl coenzyme a reductase inhibitors from crataegus pinnatifida bge," Journal of Agricultural and Food Chemistry, vol. 58, no. 5, pp. 3132-3138, 2010. 

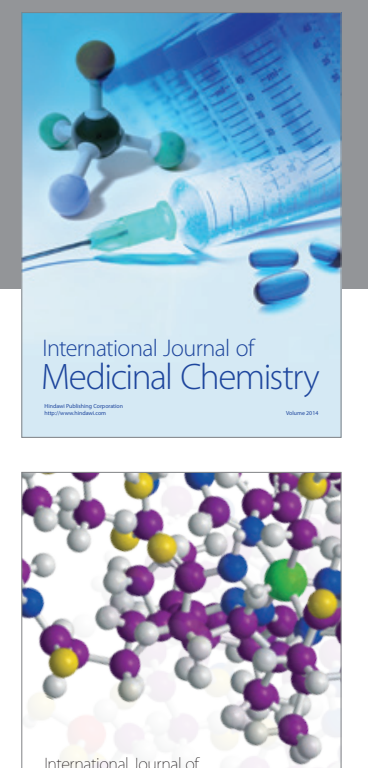

\section{Carbohydrate} Chemistry

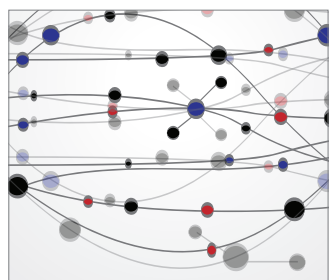

The Scientific World Journal
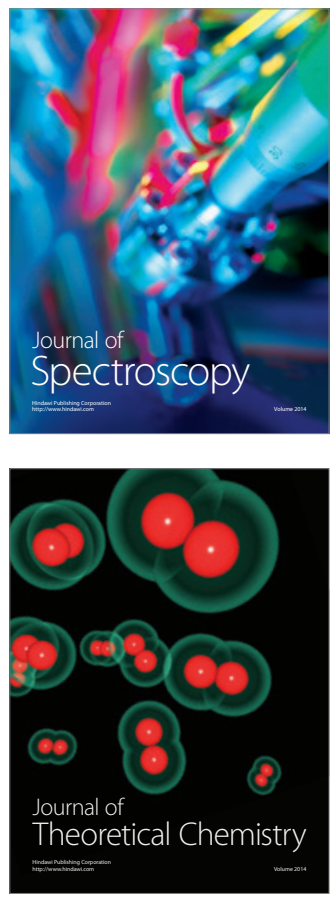
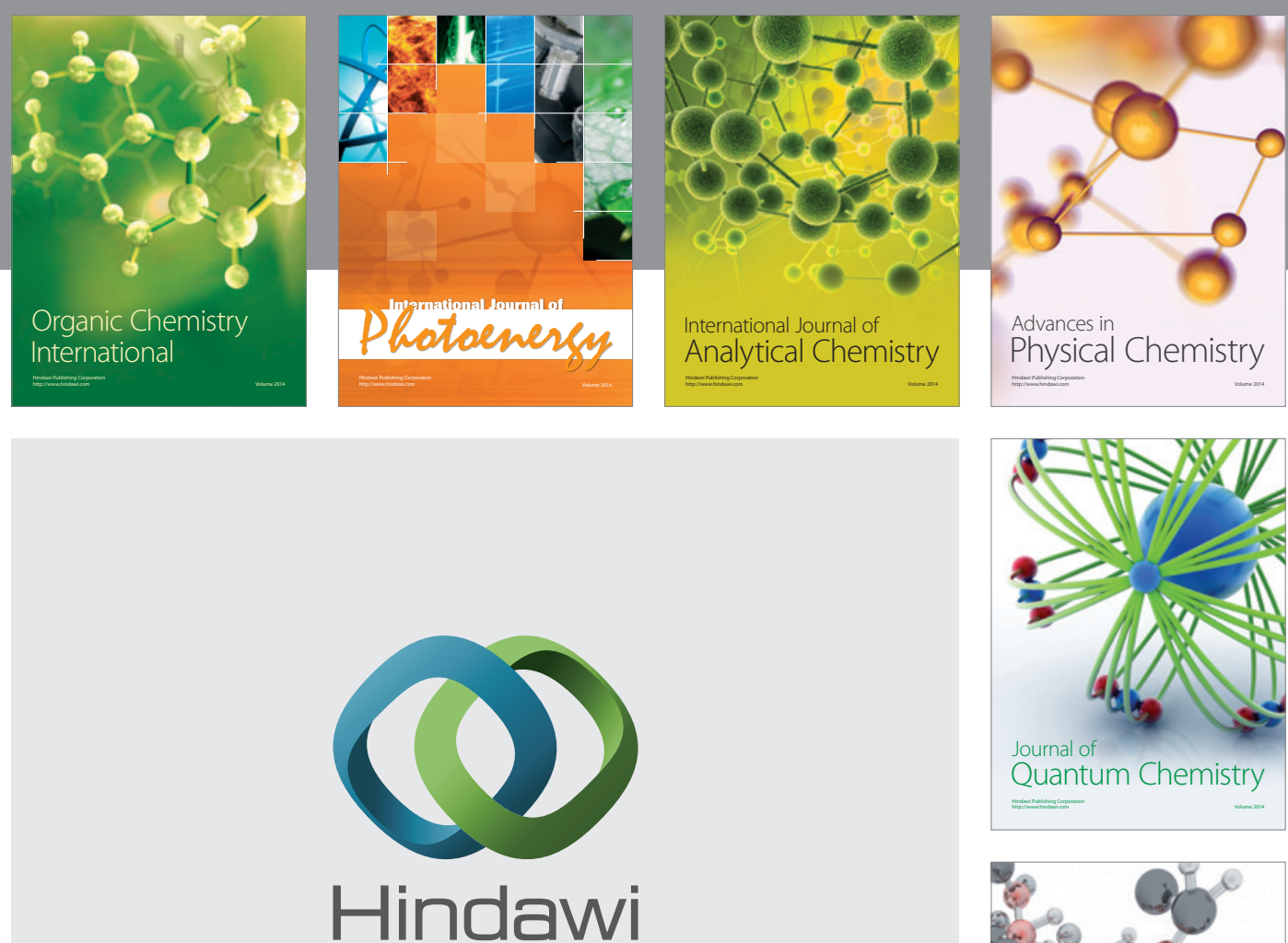

Submit your manuscripts at

http://www.hindawi.com

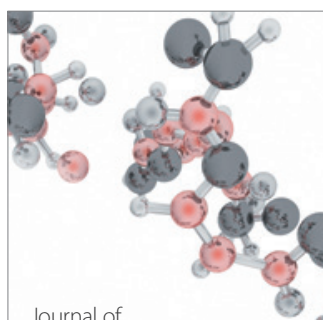

Analytical Methods

in Chemistry

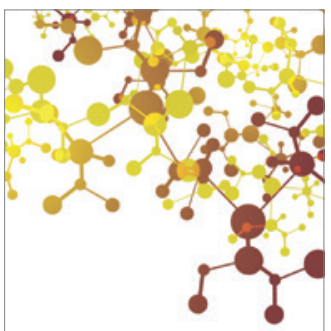

Journal of

Applied Chemistry

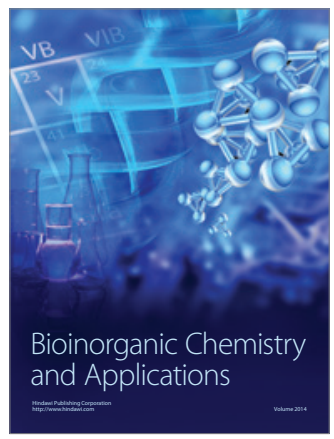

Inorganic Chemistry
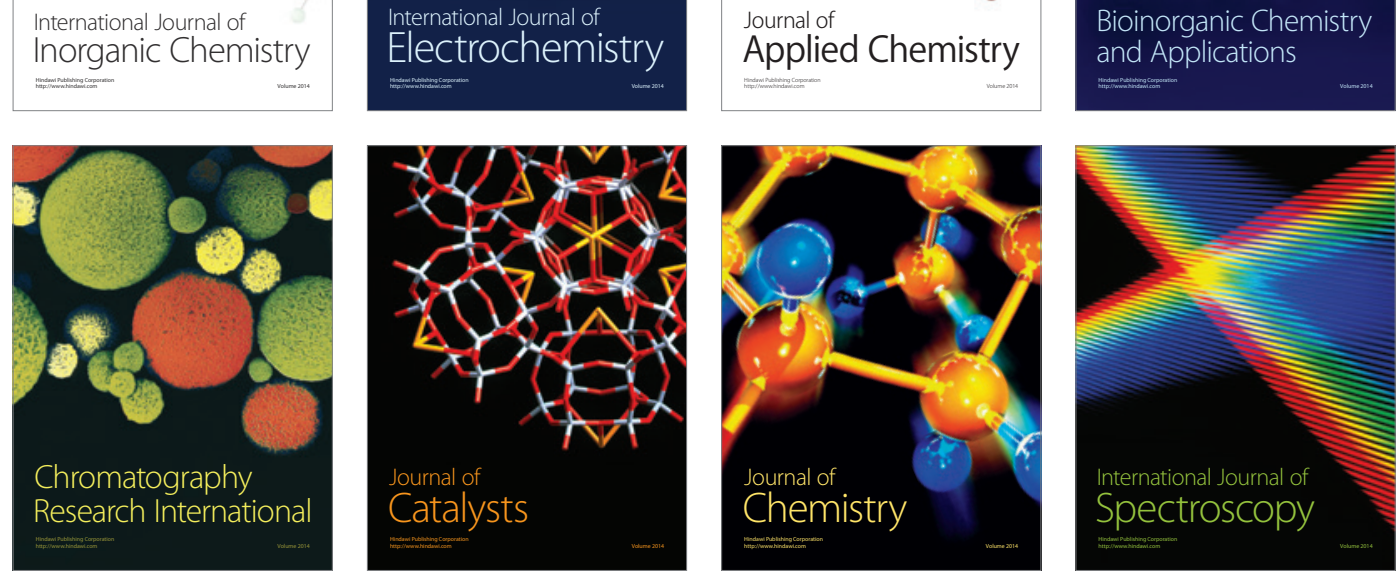